\title{
CALCULATION UNCERTAINTIES IN SPENT FUEL INVENTORY DETERMINATION
}

\author{
Tomas Czakoj $^{a, *}$, Jan Frybort $^{a}$, Martin Lovecky $^{b}$ \\ ${ }^{a}$ Czech Technical University in Prague, FNSPE, DNR, V Holesovickach 2, 18000 Prague, Czech Republic \\ ${ }^{b}$ SKODA JS a.s., Orlik 266/15, 31600 Bolevec, Plzen, Czech Republic \\ * corresponding author: tomas.czakoj@gmail.com
}

\begin{abstract}
In the depletion calculation of the nuclear fuel, the uncertainty is of utmost importance, as it affects the uncertainty of the subsequent calculation, when the calculated composition is used. The calculations are even more important when they are safety related, e. g., when determining the reactivity or emissions of radioactivity to the environment. This work covers the depletion model of Gd-2M+ fuel which was developed in ORIGEN-ARP/TRITON calculation sequences, both being parts of a SCALE 6.2.1 package. The uncertainties of the respective calculation model were determined by comparison with experimental data for both calculation sequences. The effects of operational and manufacturing uncertainties on concentration of the most important nuclides using TRITON depletion model of Gd-2M+ fuel were determined. The effect of respective uncertainties manifested in changes of composition on the multiplication factor using Monte-Carlo sequence KENO-VI were also specified.
\end{abstract}

KEYWORDS: Uncertainties, nuclear, fuel, calculation, depletion.

\section{INTRODUCTION}

The awareness of the uncertainty of a calculation is very important, especially in nuclear reactor applications. Inaccurate determination of spent fuel inventory can result in higher decay power, higher emissions or by increased reactivity which can be very dangerous.

This work estimates the accuracy of the calculation performed by comparison of experimentally determined spent nuclear fuel inventory with the calculated one. The study of influence of variation in some operational and manufacturing input aspects, such as temperature, power level or enrichment, was conducted. The respective study focuses on the spent fuel inventory determination and calculation of its multiplication factor.

\section{Calculation methods}

All calculations described in this paper were made in SCALE code system version 6.2.1 [1]. The depletion was simulated in TRITON and ORIGEN-ARP sequence, the determination of the reactivity important nuclides was carried out in TSUNAMI-2D sequence and the determination of the multiplication factor was obtained with the use of the KENO-VI stochastic sequence. Both depletion and sensitivity calculations used a multigroup version of ENDF/B VII.1 nuclear data library, KENO-VI simulation used continuous energy version of the aforementioned library [1, 2].

\subsection{DePLETION MODEL}

Two depletion models of Gd-2M+ fuel were created. The fuel used in the depletion models is currently used in VVER-440 reactors in Dukovany power plant. This fuel assembly contains fuel pins without a burnable

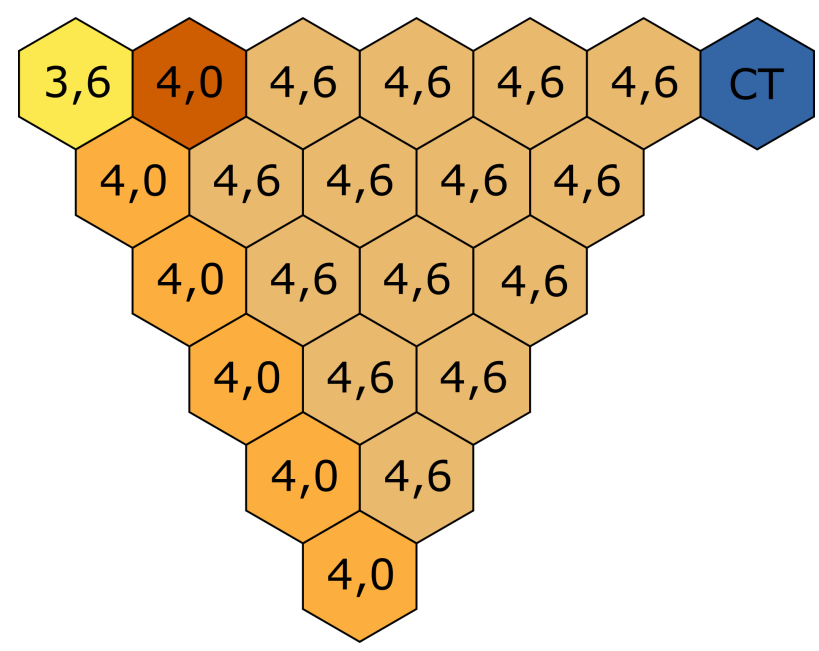

Figure 1. Enrichment of each fuel pin in the Gd2M+ fuel assembly. Numbers mean enrichment in weight fractions and the hexagon with brown color shows position of fuel pin with burnable absorber. 3].

absorber which does not have a central hole in the fuel pellets. Only exception is six fuel pins with $\mathrm{Gd}_{2} \mathrm{O}_{3}$ which contain a central hole [3].

Figure 1 shows the enrichment of each fuel pin in the respective fuel assembly, as well as the position of central tube (CT) and fuel pin with burnable absorber $\mathrm{Gd}_{2} \mathrm{O}_{3}$. The numbers in Figure 1 mean enrichment in weight fractions and the hexagon with brown color shows position of fuel pin with the burnable absorber [3].

The first depletion model was created in TRITON sequence. The detailed model included the description of geometry, composition, power history and several other important parameters affecting the accuracy of 
the calculation. This model contained an infinite array of the fuel assemblies with B1 buckling, where the assumed spectrum is identical to the critical one 4 . The depletion model used five cycles with a duration of 330 days with the specific power set to $30.535 \mathrm{~W} \mathrm{~g} \mathrm{~g}_{\mathrm{HM}}^{-1}$ and the shutdown between cycles of 35 days. The time step between depletion was 1.2 days for first 6 days of cycle, next 24 days used 6 days long time step and following 300 days used 20 days long time step.

The depletion model was originally set to maximum accuracy and after the creation of the model, many optimization calculations were conducted. Each calculation used the basic model with one modified parameter thus quantified the effect of selected reduction. In case the effect was negligible, the reduction was implemented in the final model. The optimized final model was twice faster than the basic one and the accuracy of the results was not affected [1].

The optimized parameters were time steps or Legendre order in the transport theory. Next optimized parameter was addnux, which adds trace quantities of certain groups of nuclides to the inventories of depletion materials which causes better tracking of these nuclides during the calculation. Last optimized parameter was assign. This parameter groups depletion materials. Each material of the respective group is independently depleted, but the calculation uses average cross section.

The second depletion model was made in ORIGENARP sequence. This sequence, together with the model, is very fast and simple, however it requires a data file from the previous TRITON calculation. The results are similar to results from slow detailed TRITON calculation, if an appropriate data file is used.

The ORIGEN-ARP model contained only a homogeneous composition and the power history, no other parameters are required [1].

\subsection{COMPARISON WITH EXPERIMENTAL DATA}

Because there were no avaliable experimental data of the spent Gd-2M+ fuel, it was nessesary to use the data of another fuel type. The data used for the comparison were retrieved from Project ISTC \# 3958. The goal of the project was to obtain data from the spent nuclear fuel for description of its composition [5].

The fuel assembly used in the ISTC project differed from the $\mathrm{Gd}-2 \mathrm{M}+$ fuel assembly in several aspects. The first difference was in enrichment because ISTC fuel assembly contained fuel pins with constant enrichment. Next difference was in the geometry because ISTC fuel contained central hole and also had moderately different dimensions. Because of these distinctions, the ISTC fuel assembly contained smaller amount of uranium than the Gd-2M+ fuel assembly. Another significant difference was the absence of any burnable absorber in ISTC fuel. All these diferences are listed in Table $1,[3,5,6$.

\begin{tabular}{|c|c|c|}
\hline & Gd-2M+ & ISTC \#3958 \\
\hline Fuel enrichment & $3.6 / 4.0 / 4.6 \%$ & $4.4 \%$ \\
\hline Outer fuel diameter & $0.78 / 0.76 \mathrm{~cm}$ & $0.757 \mathrm{~cm}$ \\
\hline Inner fuel diameter & $0 / 0.12 \mathrm{~cm}$ & $0.12 \mathrm{~cm}$ \\
\hline Inner cladding radius & $0.793 / 0.773 \mathrm{~cm}$ & $0.772 \mathrm{~cm}$ \\
\hline Burnable absorber & $\mathrm{Gd}_{2} \mathrm{O}_{3}$ & - \\
\hline
\end{tabular}

TABLE 1. Differences between Gd-2M+ and ISTC fuel

\begin{tabular}{|c|c|c|c|c|c|}
\hline${ }^{157} \mathrm{Gd}$ & ${ }^{156} \mathrm{Gd}$ & ${ }^{158} \mathrm{Gd}$ & ${ }^{159} \mathrm{~Tb}$ & ${ }^{155} \mathrm{Gd}$ & ${ }^{161}$ Dy \\
\hline${ }^{154} \mathrm{Gd}$ & ${ }^{239} \mathrm{Pu}$ & ${ }^{238} \mathrm{U}$ & ${ }^{241} \mathrm{Pu}$ & ${ }^{240} \mathrm{Pu}$ & ${ }^{135} \mathrm{Xe}$ \\
\hline${ }^{103} \mathrm{Rh}$ & ${ }^{143} \mathrm{Nd}$ & ${ }^{133} \mathrm{Cs}$ & ${ }^{237} \mathrm{~Np}$ & ${ }^{149} \mathrm{Sm}$ & ${ }^{131} \mathrm{Xe}$ \\
\hline${ }^{242} \mathrm{Pu}$ & ${ }^{236} \mathrm{U}$ & ${ }^{99} \mathrm{Tc}$ & ${ }^{155} \mathrm{Eu}$ & ${ }^{153} \mathrm{Eu}$ & ${ }^{151} \mathrm{Sm}$ \\
\hline${ }^{154} \mathrm{Eu}$ & ${ }^{152} \mathrm{Sm}$ & ${ }^{147} \mathrm{Pm}$ & ${ }^{145} \mathrm{Nd}$ & ${ }^{243} \mathrm{Am}$ & ${ }^{109} \mathrm{Ag}$ \\
\hline${ }^{101} \mathrm{Ru}$ & ${ }^{95} \mathrm{Mo}$ & ${ }^{238} \mathrm{Pu}$ & ${ }^{148 m} \mathrm{Pm}$ & ${ }^{150} \mathrm{Sm}$ & ${ }^{105} \mathrm{Pd}$ \\
\hline${ }^{147} \mathrm{Sm}$ & ${ }^{134} \mathrm{Cs}$ & ${ }^{105} \mathrm{Rh}$ & ${ }^{141} \mathrm{Pr}$ & ${ }^{139} \mathrm{La}$ & ${ }^{241} \mathrm{Am}$ \\
\hline${ }^{235} \mathrm{U}$ & ${ }^{234} \mathrm{U}$ & ${ }^{16} \mathrm{O}$ & ${ }^{242} \mathrm{Cm} *$ & ${ }^{244} \mathrm{Cm} *$ & ${ }^{108} \mathrm{Pd}^{*}$ \\
\hline
\end{tabular}

TABLE 2. Nuclides with big impact on the reactivity

The ISTC project \# 3958 published information about 12 samples which came from the above mentioned fuel assembly. It includes information about burnup, location of samples in the fuel assembly and also the content of certain nuclides in each sample. Based on the published information, two depletion models describing depletion of ISTC fuel were made. One model was made in the TRITON sequence and one was made in the ORIGEN-ARP sequence. The model for comparison was similar to the model described in previous section, only the geometry and composition were modified for description of the fuel assembly from the project $[5,6$.

\subsection{INFLUENCE OF UNCERTAINTIES}

\subsubsection{EFFECT ON THE SPENT FUEL INVENTORY}

Study of the influence of uncertainties was performed on changes in a content of group of nuclides in the spent fuel inventory. These nuclides were determined using the TSUNAMI sensitivity calculation which determined that said nuclides affect reactivity considerably.

The sensitivity calculation used spent fuel inventory determined by the model described in the section 2.1. The inventory was loaded into the TSUNAMI model, which was obtained from the depletion model by modification of depletion parameters to sensitivity control parameters.

Determined nuclides are listed in Table 2 Nuclides listed in this table had the minimal sensitivity of $10^{-4}$ in at least one material. Three nuclides marked with the star had smaller sensitivity, however they were accounted for because of their significant inaccuracy determined by the comparison with experimental data.

Effect of the uncertainties on the spent fuel inventory was studied by comparison of the inventory calculated without any applied uncertainty and the inventory calculated with one arbitrary uncertainty applied. Uncertainties used in this comparison include changes of parameters describing the operation of the reactor, fuel assembly geometry or composition. 


\begin{tabular}{|c|c|c|c|}
\hline Quantity & Nominal & Lower & Higher \\
\hline Moderator temperature & $555 \mathrm{~K}$ & $541 \mathrm{~K}$ & $573 \mathrm{~K}$ \\
\hline Fuel temperature & $885 \mathrm{~K}$ & $785 \mathrm{~K}$ & $985 \mathrm{~K}$ \\
\hline Boron content & $524 \mathrm{ppm}$ & $0 \mathrm{ppm}$ & $1049 \mathrm{ppm}$ \\
\hline Power level & $30.535 \mathrm{~g} \mathrm{~cm}^{-3}$ & $27.4815 \mathrm{~g} \mathrm{~cm}^{-3}$ & $33.5885 \mathrm{~g} \mathrm{~cm}^{-3}$ \\
\hline
\end{tabular}

TABle 3. Operational uncertainties

\begin{tabular}{|c|c|c|c|}
\hline Uncertainty & Nominal & Lower & Higher \\
\hline Absorber content (wt) & $3.35 \%$ & $3.2 \%$ & $3.5 \%$ \\
\hline Uranium content & $1230 / 1141 \mathrm{~g}$ & $1213 / 1124 \mathrm{~g}$ & $1247 / 1158 \mathrm{~g}$ \\
\hline Enrichment (wt) & $3.6 / 4 / 4.6 \%$ & $3.55 / 3.95 / 4.55 \%$ & $3.65 / 4.05 / 4.65 \%$ \\
\hline Outer fuel diameter & $0.78 / 0.76 \mathrm{~cm}$ & $0.777 / 0.757 \mathrm{~cm}$ & - \\
\hline Inner fuel diameter & $0 / 0.12 \mathrm{~cm}$ & $0 / 0.09 \mathrm{~cm}$ & - \\
\hline Outer cladding radius & $0.91 \mathrm{~cm}$ & $0.906 \mathrm{~cm}$ & $0.914 \mathrm{~cm}$ \\
\hline Inner cladding radius & $0.793 / 0.773 \mathrm{~cm}$ & - & $0.799 / 0.779 \mathrm{~cm}$ \\
\hline
\end{tabular}

TABLE 4. Material uncertainties

\begin{tabular}{|c|c|c|c|}
\hline Element & Content [\%] & Element & Content [\%] \\
\hline $\mathrm{N}$ & $2,9 \mathrm{E}-03$ & $\mathrm{~Pb}$ & $8,0 \mathrm{E}-04$ \\
\hline $\mathrm{F}$ & $2,2 \mathrm{E}-02$ & $\mathrm{Zn}$ & $1,1 \mathrm{E}-03$ \\
\hline $\mathrm{Na}$ & $5,2 \mathrm{E}-03$ & $\mathrm{Cu}$ & $1,1 \mathrm{E}-03$ \\
\hline $\mathrm{Mg}$ & $7,0 \mathrm{E}-03$ & $\mathrm{Ni}$ & $1,4 \mathrm{E}-02$ \\
\hline $\mathrm{Si}$ & $7,1 \mathrm{E}-03$ & $\mathrm{Co}$ & $2,0 \mathrm{E}-05$ \\
\hline $\mathrm{Cr}$ & $3,0 \mathrm{E}-03$ & $\mathrm{Fe}$ & $1,6 \mathrm{E}-02$ \\
\hline $\mathrm{Mn}$ & $2,0 \mathrm{E}-04$ & & \\
\hline
\end{tabular}

TABLE 5. Content of impurities [7]

Complete list of the used uncertainties is presented in Tables 3,4 and 5 .

All the calculated inventories had equal burnup of $50.4 \mathrm{MWd} \mathrm{kg}_{\mathrm{HM}}^{-1}$, which corresponds to the burnup of spent fuel after five years depletion in the nuclear reactor. Because of the preservation of the burnup, cases with lower or higher power level were depleted for longer or shorter time, respectively.

\subsubsection{EFFECT ON THE MULTIPLICATION FACTOR}

Effect of the uncertainty on the multiplication factor was evaluated by determination of the multiplication factor of spent fuel. The composition of this fuel was calculated in previous part.

The evaluation was made in KENO-VI 3D stochastic sequence. The model was created by loading of the composition to the Gd-2M+ depletion model and its modification for KENO-VI sequence. The calculation used 2000 neutron generations with 50000 neutrons per generation and first 50 generations being inactive. The calculation was automatically terminated once the stochastic deviation decreased below 0.00020 because of the limited available computation time.

\section{Results AND Discussion}

\subsection{Comparison With EXPERIMENTAL DATA}

Calculated content of selected nuclides in each sample was compared to the experimentally determined content. This comparison was created as a fraction of computed and experimental data, marked as $\mathrm{C} / \mathrm{E}$. An arithmetic mean of $\mathrm{C} / \mathrm{E}$ for every nuclide is in Table 6 and in Figure 2 .

As presented in table 6, the results are relatively accurate for most of the elements, such as uranium, cesium or neodymium, but for some elements the inaccuracies are larger, such as for ${ }^{108} \mathrm{Pd}$ or ${ }^{151} \mathrm{Eu}$. At the moment, there are no clear reasons for these inaccuracies and more detailed research for clarification of these inaccuracies is needed.

\subsection{INFLUENCE OF UNCERTAINTIES}

\subsubsection{EFFECT ON SPENT FUEL INVENTORY}

Figure 3 depicts changes in the spent fuel inventory after the modification of moderator temperature. Results show that the biggest changes in the content are for the isotopes with high cross section in thermal energies. This phenomenon is caused by the worsened moderation, which leads to the worsened absorption in thermal part of the spectrum.

Changes in the spent fuel inventory after modification of fuel temperature are presented in Figure 4 The effect of change of fuel temperature is smaller in comparison with the effect of change of moderator temperature, but is important to take account that change in fuel temperature is usually many times higher than changes in moderator temperature.

The change in inventory after the modification of fuel temperature is mainly caused by change of Doppler Effect. Higher temperature decreases the maximum of the resonance, which results in higher resonance absorption. Higher absorption at isotope of ${ }^{238} \mathrm{U}$ then leads to higher production of actinides such as plutonium [8].

Figure 5 shows results for changes of boron content in the moderator. It is obvious that higher concentration of boron leads to higher content of gadolinium in the spent fuel. This is caused by the worsened moderation which results in lower absorption in thermal part of the spectrum. 


\begin{tabular}{|c|c|c|c|c|c|c|c|c|}
\hline & \multicolumn{2}{|c|}{$\mathrm{C} / \mathrm{E}$} & \multicolumn{3}{|c|}{$\mathrm{C} / \mathrm{E}$} & & \multicolumn{2}{|c|}{$\mathrm{C} / \mathrm{E}$} \\
\hline Nuclide & TRITON & ORIGEN-ARP & Nuclide & TRITON & ORIGEN-ARP & Nuclide & TRITON & ORIGEN-ARP \\
\hline${ }^{234} \mathrm{U}$ & $1.03 \pm 0.09$ & $1.03 \pm 0.09$ & ${ }^{242} \mathrm{Cm}$ & $1.23 \pm 0.14$ & $1.24 \pm 0.14$ & ${ }^{149} \mathrm{Sm}$ & $0.80 \pm 0.67$ & $0.80 \pm 0.67$ \\
\hline${ }^{235} \mathrm{U}$ & $0.96 \pm 0.00$ & $0.96 \pm 0.00$ & ${ }^{244} \mathrm{Cm}$ & $1.23 \pm 0.05$ & $1.23 \pm 0.05$ & ${ }^{150} \mathrm{Sm}$ & $1.07 \pm 0.43$ & $1.07 \pm 0.43$ \\
\hline${ }^{236} \mathrm{U}$ & $0.95 \pm 0.00$ & $0.95 \pm 0.00$ & ${ }^{241} \mathrm{Am}$ & $1.17 \pm 0.01$ & $1.17 \pm 0.01$ & ${ }^{151} \mathrm{Sm}$ & $1.09 \pm 0.45$ & $1.09 \pm 0.45$ \\
\hline${ }^{238} \mathrm{U}$ & $0.99 \pm 0.00$ & $0.99 \pm 0.00$ & ${ }^{243} \mathrm{Am}$ & $0.91 \pm 0.03$ & $0.91 \pm 0.03$ & ${ }^{152} \mathrm{Sm}$ & $1.05 \pm 0.37$ & $1.04 \pm 0.37$ \\
\hline${ }^{238} \mathrm{Pu}$ & $1.19 \pm 0.01$ & $1.20 \pm 0.01$ & ${ }^{133} \mathrm{Cs}$ & $0.99 \pm 0.01$ & $0.99 \pm 0.01$ & ${ }^{155} \mathrm{Gd}$ & $1.13 \pm 0.15$ & $1.13 \pm 0.15$ \\
\hline${ }^{239} \mathrm{Pu}$ & $1.23 \pm 0.00$ & $1.23 \pm 0.00$ & ${ }^{134} \mathrm{Cs}$ & $0.94 \pm 0.01$ & $0.94 \pm 0.01$ & ${ }^{95} \mathrm{Mo}$ & $0.49 \pm 0.15$ & $0.49 \pm 0.15$ \\
\hline${ }^{240} \mathrm{Pu}$ & $1.16 \pm 0.00$ & $1.16 \pm 0.00$ & ${ }^{135} \mathrm{Cs}$ & $1.15 \pm 0.01$ & $1.10 \pm 0.01$ & ${ }^{105} \mathrm{Pd}$ & $1.13 \pm 0.62$ & $1.13 \pm 0.62$ \\
\hline${ }^{241} \mathrm{Pu}$ & $1.20 \pm 0.00$ & $1.20 \pm 0.00$ & ${ }^{137} \mathrm{Cs}$ & $0.99 \pm 0.00$ & $0.99 \pm 0.00$ & ${ }^{108} \mathrm{Pd}$ & $2.67 \pm 3.73$ & $2.67 \pm 3.73$ \\
\hline${ }^{242} \mathrm{Pu}$ & $1.14 \pm 0.01$ & $1.14 \pm 0.01$ & ${ }^{151} \mathrm{Eu}$ & $0.39 \pm 0.09$ & $0.39 \pm 0.09$ & ${ }^{109} \mathrm{Ag}$ & $0.70 \pm 0.11$ & $0.70 \pm 0.11$ \\
\hline${ }^{143} \mathrm{Nd}$ & $1.05 \pm 0.00$ & $1.05 \pm 0.00$ & ${ }^{153} \mathrm{Eu}$ & $1.12 \pm 0.73$ & $1.12 \pm 0.73$ & ${ }^{101} \mathrm{Ru}$ & $1.06 \pm 0.40$ & $1.06 \pm 0.41$ \\
\hline${ }^{145} \mathrm{Nd}$ & $1.02 \pm 0.00$ & $1.02 \pm 0.00$ & ${ }^{154} \mathrm{Eu}$ & $1.22 \pm 0.94$ & $1.22 \pm 0.94$ & ${ }^{237} \mathrm{~Np}$ & $0.79 \pm 0.01$ & $0.79 \pm 0.01$ \\
\hline${ }^{146} \mathrm{Nd}$ & $1.01 \pm 0.00$ & $1.01 \pm 0.00$ & ${ }^{155} \mathrm{Eu}$ & $1.09 \pm 0.68$ & $1.09 \pm 0.67$ & ${ }^{144} \mathrm{Ce}$ & $0.99 \pm 0.15$ & $0.99 \pm 0.15$ \\
\hline${ }^{148} \mathrm{Nd}$ & $1.01 \pm 0.00$ & $1.01 \pm 0.00$ & ${ }^{147} \mathrm{Sm}$ & $1.03 \pm 0.36$ & $1.03 \pm 0.36$ & & & \\
\hline
\end{tabular}

TABLE 6. Comparison of calculated and experimental data

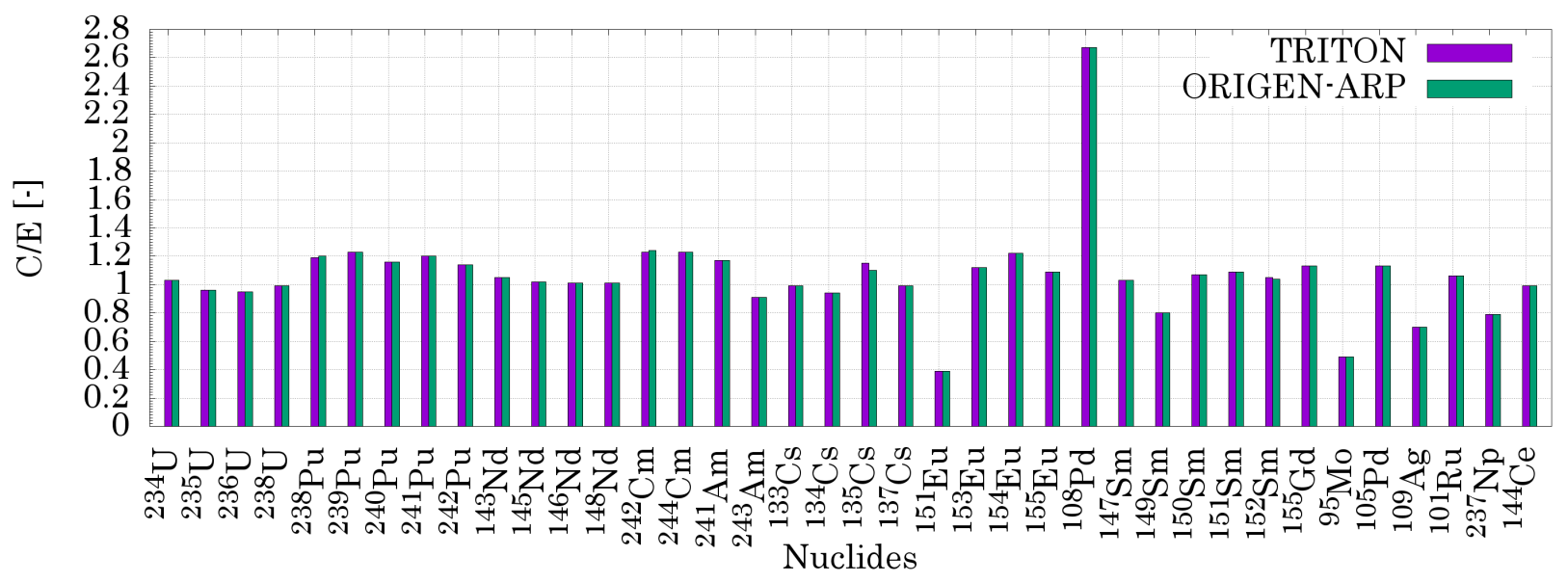

Figure 2. Comparison of calculated and experimental data

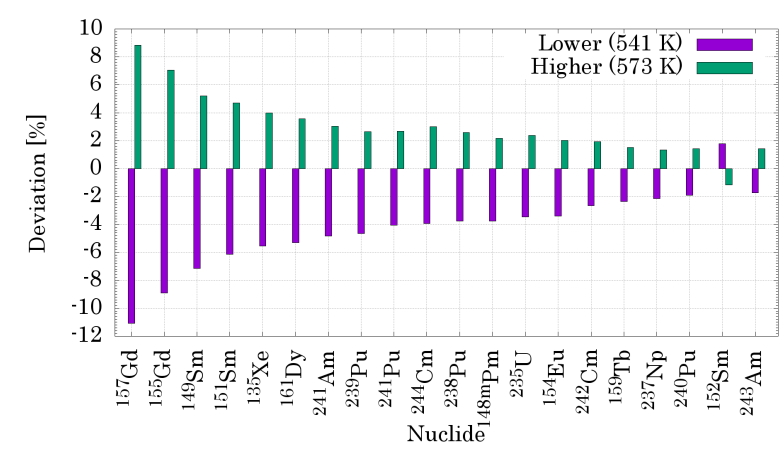

FiguRE 3. Effect of change in moderator temperature on composition.

Similar observation can be seen in the content of samarium. Both its isotopes ${ }^{149} \mathrm{Sm}$ and ${ }^{151} \mathrm{Sm}$ have a high microscopic cross section for absorption in thermal energies. Similarly to gadolinium, higher boron

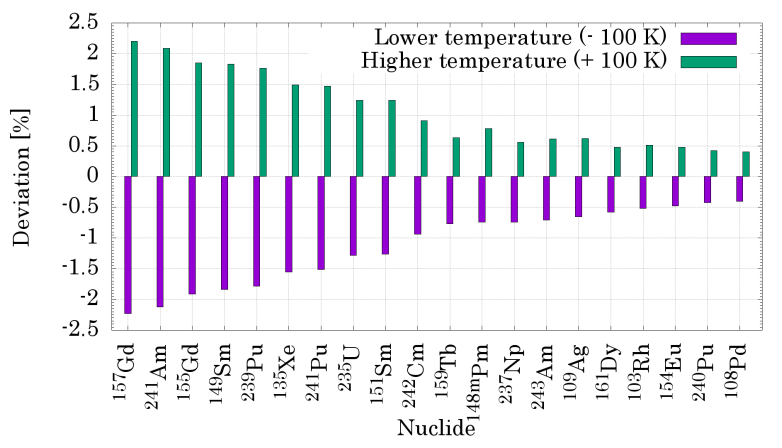

FiguRE 4. Effect of change in fuel temperature on composition.

content worsens moderation which causes lower absorption in samarium isotopes [2].

Results for different power levels are shown in Figure 6. The power level change affects only few isotopes, content of most of the isotopes remains almost un- 


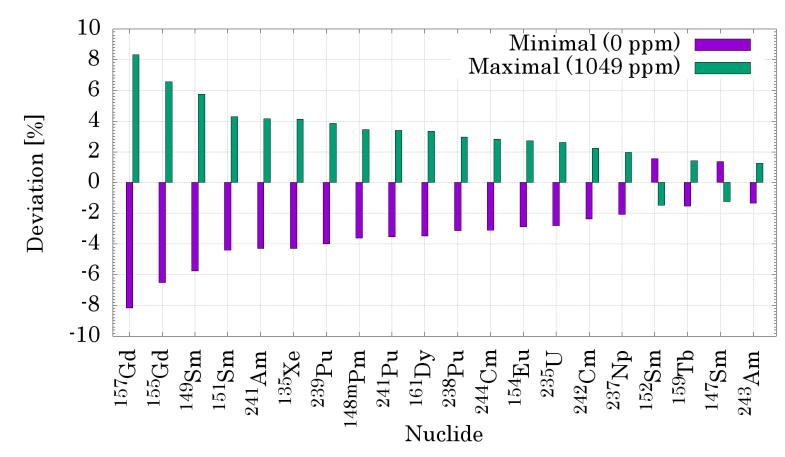

FiguRE 5. Effect of change in boron content on composition.

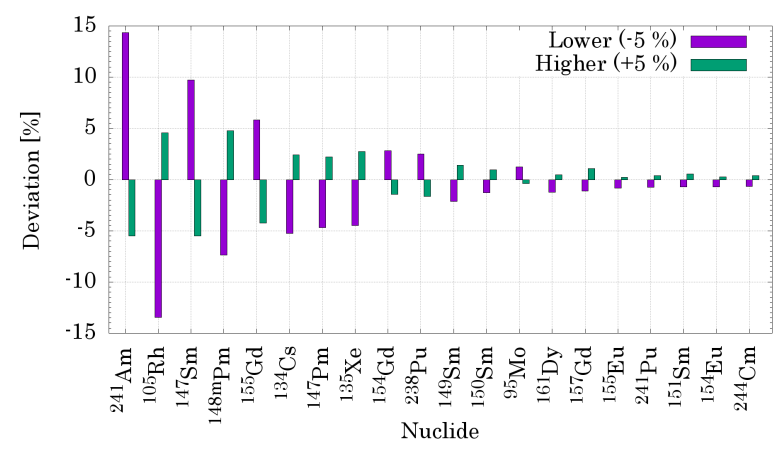

Figure 6. Effect of change in power level on composition.

changed. These changes are mainly caused by longer depletion time, which allows for a higher accumulation of certain isotopes in the spent fuel, caused by the decay of their parent nuclides. Another reason for the changes in content is connected to the higher production of short-lived fission products and its daughter isotopes for higher power levels, such as ${ }^{135} \mathrm{Xe}$ or ${ }^{105} \mathrm{Rh}$ [9].

Figure 7 shows results of impact of the variation in the $\mathrm{Gd}_{2} \mathrm{O}_{3}$ content in spent fuel. This variation affects mainly the gadolinium content in spent fuel inventory, yet it also leads to increased content of ${ }^{161} \mathrm{Dy}$ and ${ }^{159} \mathrm{~Tb}$ isotopes, due to them originating from gadolinium according to Equations (1) - (3) [10]. Effect on content of any other nuclides is negligible.

$$
\begin{aligned}
& { }^{158} \mathrm{Gd}+\mathrm{n} \rightarrow{ }^{159} \mathrm{Gd} \underset{18,479 \mathrm{~h}}{\stackrel{\beta^{-}}{\longrightarrow}}{ }^{159} \mathrm{~Tb} \\
& { }^{159} \mathrm{~Tb}+\mathrm{n} \rightarrow{ }^{160} \mathrm{~Tb}\left\{\begin{array}{l}
\underset{\beta^{-}}{72,3 \mathrm{~d}}{ }^{160} \mathrm{Dy}+\mathrm{n} \rightarrow{ }^{161} \mathrm{Dy} \\
+\mathrm{n} \rightarrow{ }^{161} \mathrm{~Tb} \underset{6,906 \mathrm{~d}}{\stackrel{\beta^{-}}{\rightarrow}}{ }^{161} \mathrm{Dy}
\end{array}\right. \\
& { }^{160} \mathrm{Gd}+\mathrm{n} \rightarrow{ }^{161} \mathrm{Gd} \underset{3,66 \mathrm{~min}}{\stackrel{\beta^{-}}{\longrightarrow}}{ }^{161} \mathrm{~Tb} \underset{6,906 \mathrm{~d}}{\stackrel{\beta^{-}}{\longrightarrow}}{ }^{161} \mathrm{Dy}
\end{aligned}
$$

Figure 8 shows results of impact of change in the uranium content. As expected, the higher initial content of uranium leads to higher final content of all

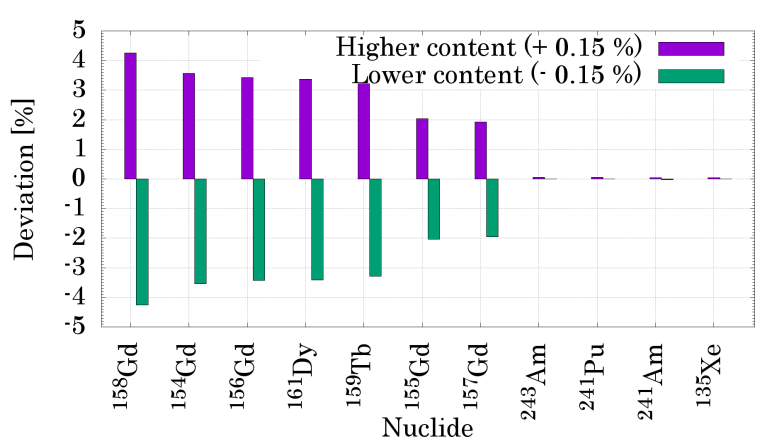

Figure 7. Effect of change in $\mathrm{Gd}_{2} \mathrm{O}_{3}$ content on composition.

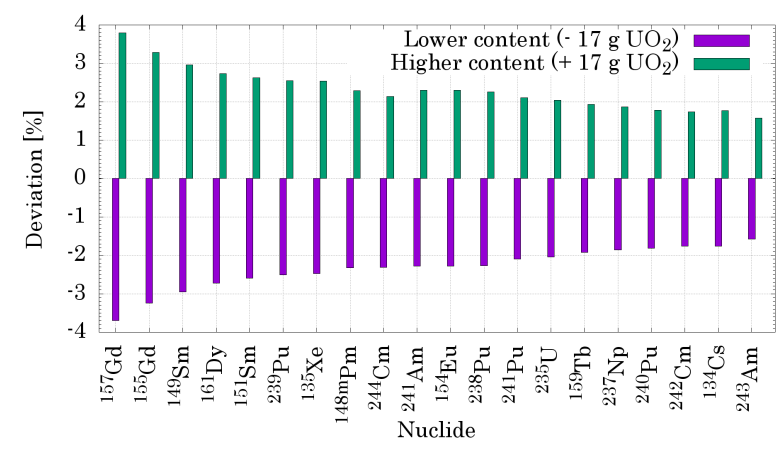

Figure 8. Effect of change in uranium content on composition.

investigated nuclides, however, the difference between content of various nuclides is visible.

The results of variations in the enrichment are depicted in Figure 9. The changes in uranium isotopes content were expected because their initial content was also modified together with the enrichment [11.

Variations in content of isotopes ${ }^{242} \mathrm{Am},{ }^{244} \mathrm{Cm}$ or ${ }^{242} \mathrm{Pu}$ are also observed. Their content in spent fuel is higher with lower enrichment. This phenomenon is caused by their production from the ${ }^{238} \mathrm{U}$ because the initial content of this isotope also varies with enrichment. Another effect of change in enrichment is also connected to modification of neutron spectrum because lower content of ${ }^{238} \mathrm{U}$ leads to lower parasitic absorption.

Figures 10 and 11 show results for changes in fuel and cladding radii. The impact of fuel radius change is negligible, which is probably caused by modification of fuel density made with the objective of preservation of fuel content. Bigger effects observed for fuel pins without gadolinium are obviously caused by their higher number in the fuel assembly.

Effect of modification of outer cladding radius is higher, which is caused by change of the amount of moderator near to the fuel pin. This change leads to better (or worse) moderation and subsequently to a modification of the neutron spectrum. Effect of variation of inner cladding radius is negligible because it only changes the amount of cladding material, which has only small influence on neutrons. 


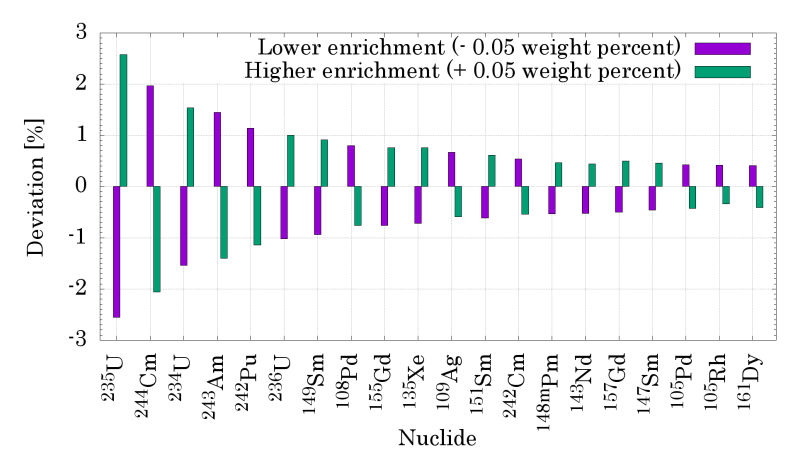

Figure 9. Effect of change in enrichment on composition.

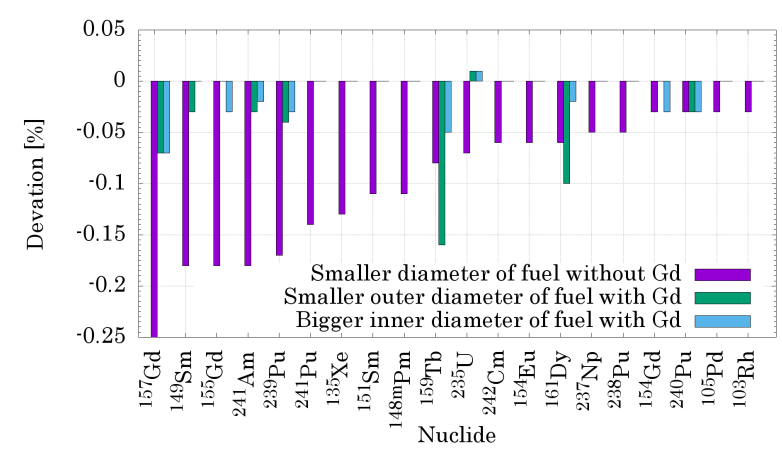

FIgURE 10. Effect of change in fuel radius

Figure 12 shows the effect of impurities in fuel. This effect is both positive and negative and for most applications, it can be considered negligible. Nevertheless it is possible to find some cases, in which the impurities can be important. For example, content of nitrogen can lead to production of radioactive ${ }^{14} \mathrm{C}$, which may have impact on the overall activity 12 .

\subsubsection{EFFECT ON MULTIPLICATION FACTOR}

Effect of the operational uncertainties was tested only with investigated uncertainty included in the depletion simulation. This means that the determination of multiplication factor is not influenced by presence of the uncertainty, but it is influenced only by change in inventory. Results of this calculation can by seen in Figure 13

The biggest impact definitely comes from the change of boron content in the moderator. Much smaller, but also important is the effect of change in the moderator temperature. Other uncertainties are of smaller importance. Both this effects are mainly caused by modification of content of nuclides with high cross section for absorption such as ${ }^{155} \mathrm{Gd},{ }^{157} \mathrm{Gd},{ }^{149} \mathrm{Sm}$ and ${ }^{151} \mathrm{Sm}$ which negatively influence neutron balance [2].

Figure 14 shows the influence of the material uncertainties on the multiplication factor. This influence has smaller importance than the operational uncertainties. The most important uncertainty is initial enrichment of the fuel, which will be mainly caused by change in final content of fissile isotope ${ }^{235} \mathrm{U}$. Second

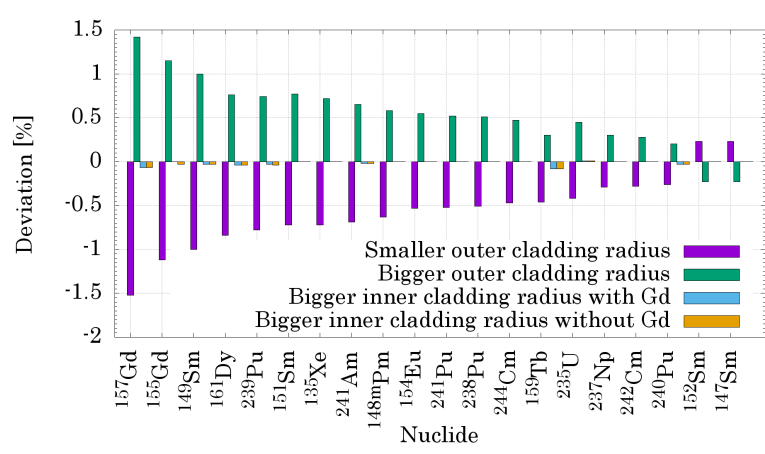

FiguRE 11. Effect of change in cladding radius

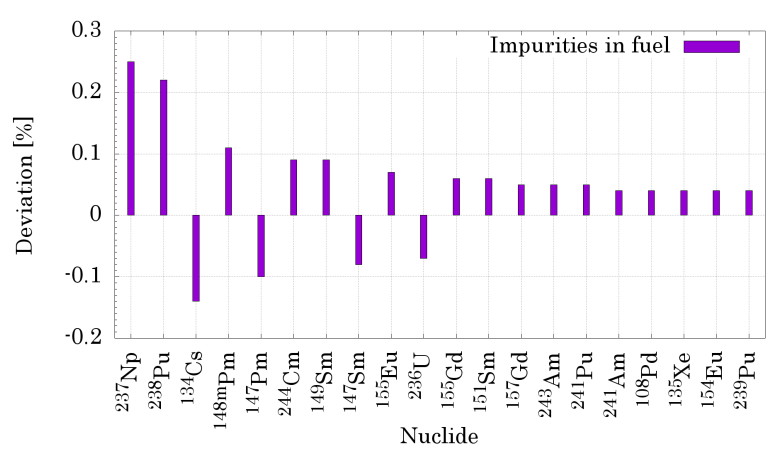

FIGURE 12. Effect of impurities in the fuel

biggest effects comes from different initial uranium content, which can probably mainly assigned to change in boron content together with changed content of fissile isotopes of plutonium and uranium.

Figure 15 shows impact of changes in geometry. These uncertainties have only small importance and the most significant is the change in the outer diameter of fuel with gadolinium absorber together with the change in its inner cladding diameter.

\section{Conclusions}

Two depletion models of Gd-2M+ fuel were created and the TRITON model was optimized for faster calculation. This model was used for the study of influence of the operational and manufacturing uncertainties.

Comparison of computed and experimental data was conducted for both used depletion sequences. No important difference in results from both sequence was found. Obtained results were relatively accurate, but few nuclides, such as ${ }^{108} \mathrm{Pd}$ or ${ }^{151} \mathrm{Eu}$, with inaccurate determination were found.

The dependence between the inaccuracy of ${ }^{108} \mathrm{Pd}$ or ${ }^{151} \mathrm{Eu}$ and between the group of tested uncertainties was not found. On the contrary, the sensitivity of ${ }^{242} \mathrm{Cm}$ and ${ }^{244} \mathrm{Cm}$ content to the boron content in the moderator and to the moderator temperature was found, which is caused by modification of neutron spectrum.

The influence of uncertainties on the spent fuel inventory and the multiplication factor was investigated. The determination of the multiplication factors has 


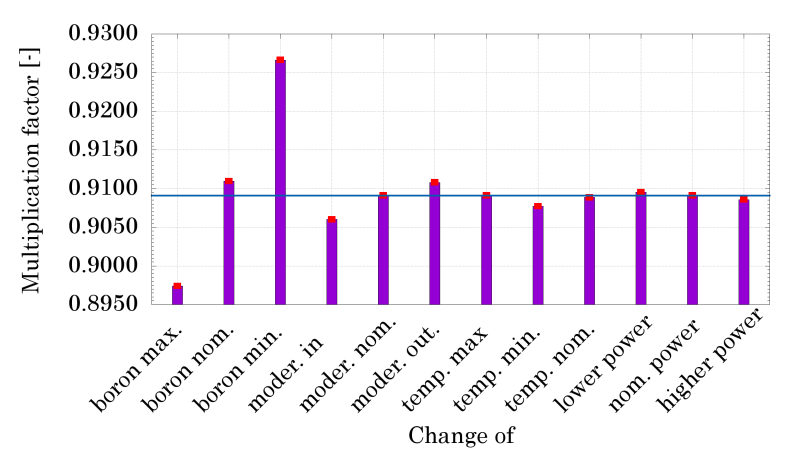

FiguRE 13. Effect of operational uncertainties on multiplication factor - only with uncertainty included in fuel depletion

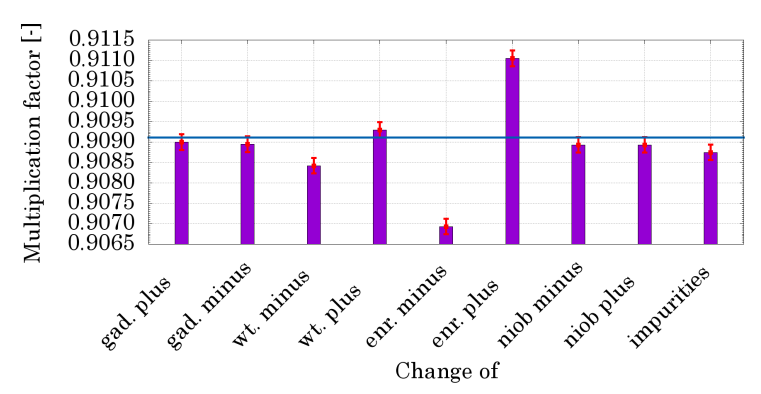

Figure 14. Effect of material uncertainties on multiplication factor

allowed for a comparison of importance of each uncertainty. It was found that most important are the operational uncertainties, especially boron content in the moderator and the moderator temperature. Although fuel temperature change seems to be much low important than the previously mentioned, it is important to remember that fuel temperature changes are much high than the moderator temperature changes. Importance of other investigated operational uncertainties is much lower than the importance of the previous.

Furthermore, it was discovered that in order to apply the conservative approach, it is necessary to set up lower boron content and higher temperature of moderator. This approach leads in faster depletion of gadolinium burnable absorber which leads in lower absorption.

On the contrary, higher fuel temperature leads in higher gadolinium content, but this effect is prevailed by higher production of fissile isotopes of plutonium together with lower ${ }^{235} \mathrm{U}$ depletion. Due to this fact, higher fuel temperature is more conservative.

Effect of all manufacturing uncertainties is lower than the most important operational uncertainties. The most important is correct set up of the enrichment and the uranium content in fuel. It is conservative to overestimate both values.

\section{REFERENCES}

[1] B. T. Rearden, M. A. Jessee. SCALE code system 6.2.1. Tech. rep., 2016. DOI:10.2172/1326509

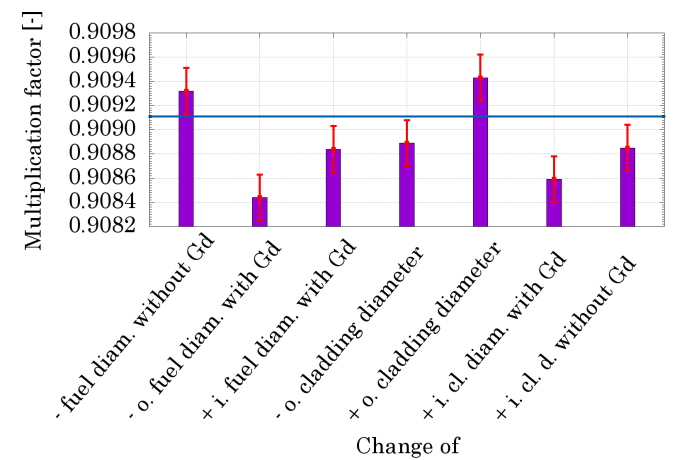

FigURE 15. Effect of uncertainties of geometry on multiplication factor

[2] M. Chadwick, M. Herman, P. Obložinský, et al. ENDF/B-VII.1 nuclear data for science and technology: Cross sections, covariances, fission product yields and decay data. Nuclear Data Sheets 112(12):2887 - 2996, 2011. Special Issue on ENDF/B-VII.1 Library, DOI:10.1016/j.nds.2011.11.002

[3] P. Mikolas, Z. Fakezasova, M. Sasek, et al. Zmena casti ppbz pro zavedeni paliva gd-2m+edu: 4.3 jaderne charakteristiky, 2013.

[4] J. Leppanen, M. Pusa, E. Fridman. Overview of methodology for spatial homogenization in the serpent 2 monte carlo code. Annals of Nuclear Energy 96(Supplement C):126 - 136, 2016. DOI:https://doi.org/10.1016/j.anucene.2016.06.007

[5] S. Pavlov. Investigation of the VVER-440 Fuel Burnup and Nuclide Composition for the Use in Burnup Credit-Related Tasks (BUC-II) Final Scientific Technical Report on Task 5, Dimitrovgrad. ISTC Project \#3958p, Dimitrovgrad, 2011.

[6] L. Markova, F. Havluj. Specification of simplified benchmark based on \#3958 ISTC PIE. Nuclear Research Institute at Rez, Czech Republic, 2011.

[7] L. Pajo. UO2 Fuel pellet impurities, pellet surface roughness and $n(180) / n(160)$ ratios, applied to nuclear forensic science. Ph.D. thesis, University of Helsinki, Faculty of Science, Department of Chemistry, 2011.

[8] J. R. Lamarsh. Introduction to Nuclear Engineering, 2nd Edition. Addison-Wesley, 1983.

[9] B. Hermansky. Dynamika jadernych reaktoru : docasna vysokoskolska ucebnice pro studenty obor jaderne inzenyrstvi. Ceskoslovenska redakce VN MON, Praha, 1st edn., 1987. Vydavatel: CSR. Ministerstvo skolstvi, mladeze a telovychovy.

[10] Y. Tanoue, T. Yokoyama, M. Ozawa. Resource evaluation of heavy rare earth derived from the spent gd2o3 burnable poison in LWRs. Journal of Energy and Power Engineering 10(4), 2016. DOI:10.17265/1934-8975/2016.04.004.

[11] S. Cerne, O. Hermann, R. Westfall. Reactivity and isotopic composition of spent PWR (pressurized-waterreactor) fuel as a function of initial enrichment, burnup, and cooling time. Tech. rep., 1987. DOI:10.2172/5561567

[12] M.-S. Yim, F. Caron. Life cycle and management of carbon-14 from nuclear power generation. Progress in Nuclear Energy 48(1):2 - 36, 2006.

DOI:https://doi.org/10.1016/j.pnucene.2005.04.002 